\title{
Vigor de sementes de trevo vermelho submetidas a estresse salino
}

\author{
Vigor of red clover seeds under salinity stress
}

\author{
Giselle Regina Rodolfo, Cileide Maria Medeiros Coelho*, Natalia Carolina Moraes Ehrhardt-Brocardo, \\ Clovis Arruda de Souza, Karla Katy Belizário
}

Universidade do Estado de Santa Catarina, Lages, SC, Brasil. Autor para correspondência: cileide.souza@udesc.br

Submissão: 14/04/2020 / Aceite: 02/09/2020

\begin{abstract}
RESUMO
O teste de envelhecimento acelerado é de grande importância para expressar o potencial fisiológico das sementes. O objetivo do trabalho foi determinar o vigor de sementes de trevo vermelho das cultivares Quiniquelli e Estanzuela 116 pelo teste do envelhecimento acelerado sob estresse hídrico e salino. Para tal, as sementes foram expostas a solução hídrica e salina com $\mathrm{NaCl}(40 \%)$ nos tempos de 12, 24, 36, 48 e $72 \mathrm{~h}$ a $42^{\circ} \mathrm{C}$ e, em seguida, avaliadas pelo teste de envelhecimento acelerado. Foram medidos os comprimentos de 15 plântulas normais de cada uma das quatro repetições de ambas as cultivares e determinada a massa seca das plântulas $\left(48 \mathrm{~h} / 60^{\circ} \mathrm{C}\right)$. Após $12,24 \mathrm{e} 36 \mathrm{~h}$ de envelhecimento em solução salina o vigor foi superior à média de $84,5 \%$ para ambas cultivares. No teste conduzido com água, o tempo de $36 \mathrm{~h}$ foi suficiente para estressar as sementes. O tempo de envelhecimento acelerado que melhor caracterizou o vigor de sementes das cultivares Quiniquelli e Estanzuela 116 foi o de $48 \mathrm{~h}$ sob temperatura de $42{ }^{\circ} \mathrm{C}$ com o uso de solução saturada de $\mathrm{NaCl}$, sendo o mais indicado para as sementes de trevo vermelho.
\end{abstract}

PALAVRAS-CHAVE: Trifolium pratense, qualidade fisiológica, leguminosa forrageira, solução salina.

\begin{abstract}
The accelerated aging test is a considerably important method for measuring the physiological potential of seeds. This study sought to apply the accelerated aging test to determine the vigor of red clover seeds of the Quiniquelli and Estanzuela 116 cultivars under water and salinity stress conditions. Accordingly, the seeds were aged for $12,24,36,48$, and 72 hours at $42{ }^{\circ} \mathrm{C}$ in water and a saturated salt solution $(40 \%$ $\mathrm{NaCl}$ ) and then assessed by the accelerated aging test. The lengths of 15 normal seedlings from each of the four replicates for both cultivars were measured, and the seedlings' dry mass $\left(48 \mathrm{~h} / 60{ }^{\circ} \mathrm{C}\right)$ was determined. After aging 12, 24, and 36 hours in a saturated salt solution, vigor was above the average of $84.5 \%$ for both cultivars. In the test conducted with water, 36 hours were enough to stress the seeds. The accelerated aging time that best represented the vigor of the seeds of the Quiniquelli and Estanzuela 116 cultivars was 48 hours at $42{ }^{\circ} \mathrm{C}$ in the saturated $\mathrm{NaCl}$ solution, thus being the most suitable for red clover seeds.
\end{abstract}

KEYWORDS: Trifolium pratense, physiological quality, forage legume, saturated salt solution.

\section{INTRODUÇÃO}

A utilização intensiva de sementes de forrageiras na formação de pastagens no Brasil é relativamente recente. Ao substituir, em grande parte, a propagação vegetativa, o maior uso de sementes ocorreu a partir dos primeiros anos da década de 70, por meio de incentivos e campanhas realizadas por instituições governamentais e privadas, visando melhoramento das pastagens brasileiras, mediante espécies mais produtivas (NERY et al. 2012).

O trevo vermelho é uma espécie importante para as regiões do Planalto e dos Campos de Cima da Serra, consorciando-se bem com azevém, aveia preta, centeio, festuca e outras leguminosas (FONTANELI et al. 2012). No sul do Brasil esta forrageira está adaptada a variadas condições de solo e clima, e suas sementes permitem rápido estabelecimento em relação a outras leguminosas (CARVALHO et al. 2010). Apresenta bom potencial de produção de matéria seca e qualidade de forragem, sendo indicada para complementar a dieta dos animais durante a estação fria do ano (MONTARDO et al. 2003).

O estabelecimento da cultura a campo e a produtividade estão diretamente relacionados com a 
qualidade fisiológica das sementes. O vigor é um dos principais atributos da qualidade fisiológica das sementes a ser considerado na implantação de uma cultura, devido a influência que pode ter no crescimento e rendimento das plantas (ROSSI et al. 2017). Os testes de vigor são metodologias que estimulam a sensibilidade das sementes de modo a expressar com maior precisão sua qualidade fisiológica. Dentre os testes de vigor disponíveis, o teste de envelhecimento acelerado é um dos mais estudados e recomendados para diversas espécies cultivadas (FREITAS et al. 2018), devido à sua precisão e sensibilidade em detectar diferenças de qualidade entre lotes de sementes com germinação semelhante (PEREIRA et al. 2015) e possuir relação com o potencial de conservação das sementes (RADKE et al. 2016).

Um aspecto de grande relevância para o teste de envelhecimento acelerado é o tamanho da semente. Sementes menores tais como as de trevo vermelho absorvem água de forma rápida e desuniforme em relação às sementes maiores durante o período de envelhecimento, o que pode influenciar na precisão dos resultados. Nesta perspectiva, uma alternativa para a condução do teste de envelhecimento acelerado com sementes de trevo vermelho é a substituição da água por solução salina (RADKE et al. 2016).

São escassos os estudos envolvendo tecnologia e produção de sementes de trevo vermelho, bem como resultados relacionados ao vigor, sendo este fator fundamental para o desempenho das sementes a campo e posterior produtividade da cultura. Desta maneira, existe a necessidade da padronização de testes visando alcançar resultados precisos que auxiliem os programas de controle de qualidade de sementes.

Assim, é de fundamental importância avaliar a qualidade fisiológica das sementes de trevo vermelho, bem como o período de envelhecimento que melhor caracteriza o seu vigor, buscando otimizar o tempo de execução das análises em laboratório e avaliar o potencial de desempenho das sementes a campo. Diante do exposto, o objetivo do trabalho foi determinar o vigor de sementes de trevo vermelho das cultivares Quiniquelli e Estanzuela 116 pelo teste do envelhecimento acelerado utilizando solução hídrica e salina com diferentes tempos de incubação.

\section{MATERIAL E MÉTODOS}

O trabalho foi conduzido a campo e em laboratório. Visando obter as sementes com a mesma origem e mesmas condições de armazenamento, realizou-se a semeadura a campo das cultivares trevo vermelho Quiniquelli e Estanzuela 116, em 2015 no município de Lages, SC, em área experimental sediada no Centro de Ciências Agroveterinárias - CAV/UDESC. A semeadura ocorreu no mês de abril, que segundo SANTOS et al. (2012), é o período ideal para a implantação da cultura, com quatro repetições de oito linhas com 50 metros cada, seguindo os padrões regidos pelo Ministério da Agricultura Pecuária e Abastecimento (MAPA) para um campo de produção de sementes. A colheita e posteriores análises foram realizadas em 2016, quando as inflorescências apresentaram coloração marrom escuro indicativo da maturação. Foram coletadas manualmente as quatro linhas centrais e eliminados $50 \mathrm{~cm}$ das extremidades seguindo os padrões do MAPA.

No Laboratório de Análise de Sementes da Universidade do Estado de Santa Catarina - UDESC/CAV, foi determinada através de uma porção representativa das sementes colhidas, a obtenção da amostra média que para o trevo vermelho é de $50 \mathrm{~g}$ (MAPA 2005). Também determinou-se o teor de umidade das sementes e posteriormente as mesmas foram armazenadas em câmara seca $\left(10{ }^{\circ} \mathrm{C}\right.$ e UR $\left.70 \%\right)$. A obtenção da amostra de trabalho foi realizada através da homogeneização e redução da amostra média utilizando quarteador e as sementes separadas por peso em quatro repetições. Para caracterizar a qualidade fisiológica, as sementes foram submetidas ao teste de envelhecimento acelerado com solução saturada de $\mathrm{NaCl}$.

O teste do envelhecimento acelerado foi realizado segundo metodologia citada por MARCOS FILHO (1999), utilizando-se uma adaptação com copos plásticos perfurados para comportar as sementes de tamanho reduzido. Sobre superfície perfurada do copo plástico, foram distribuídas as sementes, a qual foi sobreposta em outro recipiente de tal forma que as sementes não tivessem contato com a solução salina. A solução foi obtida pela proporção $40 \mathrm{~g}$ de $\mathrm{NaCl} / 100 \mathrm{~mL}$ de água ( $40 \%$ de concentração), estabelecendo, com isso, ambiente com umidade relativa do ar de 76\%, conforme procedimentos propostos por JIANHUA \& McDONALD (1996). Os copos foram tampados e levados à câmara de envelhecimento acelerado por 12 , 24, 36, 48 e $72 \mathrm{~h}$ a temperatura de $42 \pm 1^{\circ} \mathrm{C}$.

Após o teste do envelhecimento acelerado, as sementes foram dispostas em número de 100 dentro de caixas de acrílico tipo gerbox, com quatro repetições para cada cultivar e sobre papel mata-borrão 
umedecidos com duas vezes e meia o seu peso seco. Posteriormente, as caixas gerbox foram levadas à câmara de germinação a $20 \pm 2{ }^{\circ} \mathrm{C}$ com fotoperíodo de $12 \mathrm{~h}$, onde a primeira verificação foi feita no quarto dia, e a última no décimo dia. Os resultados foram expressos em porcentagem de plântulas normais, anormais e sementes mortas segundo as Regras de Análise de Sementes - RAS (BRASIL 2009).

O teor de umidade foi determinado antes e após os testes de envelhecimento acelerado, pelo método da estufa a $105 \pm 3{ }^{\circ} \mathrm{C}$, durante $24 \mathrm{~h}$, utilizando-se duas repetições de $5,0 \mathrm{~g}$ de sementes, seguindo as especificações do RAS (BRASIL 2009). Os resultados foram expressos em porcentagem. O comprimento de plântulas foi avaliado conforme metodologia descrita por NAKAGAWA (1999), onde, após o envelhecimento e germinação, foram medidos o comprimento total (parte aérea e raiz) de 15 plântulas normais por repetição, com o auxílio de paquímetro modelo universal. Os resultados foram expressos em centímetros. Para a obtenção da massa seca as 15 plântulas foram submetidas a $60^{\circ} \mathrm{C}$ em estufa por $48 \mathrm{~h}$, sendo pesadas antes e após a secagem.

O delineamento experimental utilizado foi inteiramente casualizado com quatro repetições. Os dados foram submetidos à ANOVA e as médias de cada cultivar nos cinco tempos de envelhecimento foram comparadas pelo teste de Tukey a $5 \%$ de probabilidade. Para a execução das análises estatísticas foi utilizado o programa estatístico SAS, versão 9.0 .

\section{RESULTADOS E DISCUSSÃO}

A partir dos resultados obtidos pode-se observar uma variação no grau de umidade das sementes com os diferentes tempos de envelhecimento acelerado com exceção para as sementes da cultivar Quiniquelli submetidas a solução salina, a qual não demonstrou variações significativas. Constatou-se também que o grau de umidade das sementes submetidas ao teste de envelhecimento acelerado com água resultou em valores superiores aos do envelhecimento realizado com solução salina, onde a partir de 24 horas houve uma diferença do grau de umidade de 15,2\% na média das duas cultivares (Tabela 1). Estes resultados corroboram com os encontrados por SILVA et al. (2017) em sementes de crotalária submetidas ao teste de envelhecimento acelerado, onde o grau de umidade das sementes aumentou, porém utilizando solução salina os valores foram menores. No trabalho realizado por estes autores pode-se constatar uma diferença no grau de umidade das sementes utilizando-se sal e água, na média de $26,5 \%$. Também em trabalho conduzido com sementes de tamanho reduzido como de cenoura, RODO et al. (2000) observaram que o grau de umidade das sementes expostas à solução saturada de $\mathrm{NaCl}$ foi menor, com diferença no grau de umidade na média de $31,2 \%$.

Tabela 1. Grau de umidade de sementes de trevo vermelho das cultivares Quiniquelli e Estanzuela 116 em função dos tempos de envelhecimento acelerado utilizando solução salina e água.

Table 1. Moisture content of red clover seeds of the Quiniquelli and Estanzuela 116 cultivars as related to accelerated aging times in a saturated salt solution and water.

\begin{tabular}{lcccccc}
\hline & \multicolumn{5}{c}{ Tempo de envelhecimento acelerado (h) } \\
\cline { 2 - 7 } Cultivar & 0 & 12 & 24 & 36 & 48 & 72 \\
\cline { 2 - 7 } & $5,50 \mathrm{a}$ & $5,50 \mathrm{a}$ & $10,33 \mathrm{a}$ & $8,00 \mathrm{a}$ & $8,97 \mathrm{a}$ & $6,87 \mathrm{a}$ \\
\hline Quiniquelli & $10,00 \mathrm{bc}$ & $10,00 \mathrm{bc}$ & $16,73 \mathrm{a}$ & $12,00 \mathrm{abc}$ & $14,45 \mathrm{ab}$ & $7,82 \mathrm{c}$ \\
Estanzuela 116 & \multicolumn{5}{c}{ Grau de umidade (\%) - água } \\
\hline & $5,50 \mathrm{c}$ & $5,50 \mathrm{c}$ & $22,40 \mathrm{~b}$ & $23,00 \mathrm{ab}$ & $27,00 \mathrm{a}$ & $25,05 \mathrm{ab}$ \\
\hline Quiniquelli & $10,00 \mathrm{c}$ & $10,00 \mathrm{c}$ & $30,18 \mathrm{ab}$ & $31,00 \mathrm{ab}$ & $31,50 \mathrm{a}$ & $24,83 \mathrm{~b}$
\end{tabular}

Médias seguidas pela mesma letra na linha não diferem estatisticamente entre si pelo teste de Tukey ao nível de $5 \%$ de probabilidade.

A desuniformidade e a velocidade de absorção de água entre sementes de uma mesma amostra podem interferir na precisão dos resultados do teste. Por este motivo, alternativas tem sido estudadas, como a substituição da água colocada no interior dos recipientes por soluções saturadas de $\mathrm{NaCl}, \mathrm{KCl}$ ou $\mathrm{NaBr}$. $\mathrm{O}$ uso de método modificado de envelhecimento artificial para sementes pequenas retarda a absorção de água, promovendo efeitos menos drásticos e impedindo o crescimento de microrganismos (JIANHUA \& 
McDONALD 1996). Vale ressaltar que no presente trabalho pode-se constatar a presença de fungos nas amostras submetidas ao envelhecimento acelerado com água.

O vigor por envelhecimento acelerado das sementes de trevo vermelho das cultivares Quiniquelli e Estanzuela 116 após os tempos de envelhecimento correspondentes a 12, 24 e 36 h em solução salina (Figura 1) foi superior aos valores de germinação médios de 85 e $84 \%$, respectivamente.
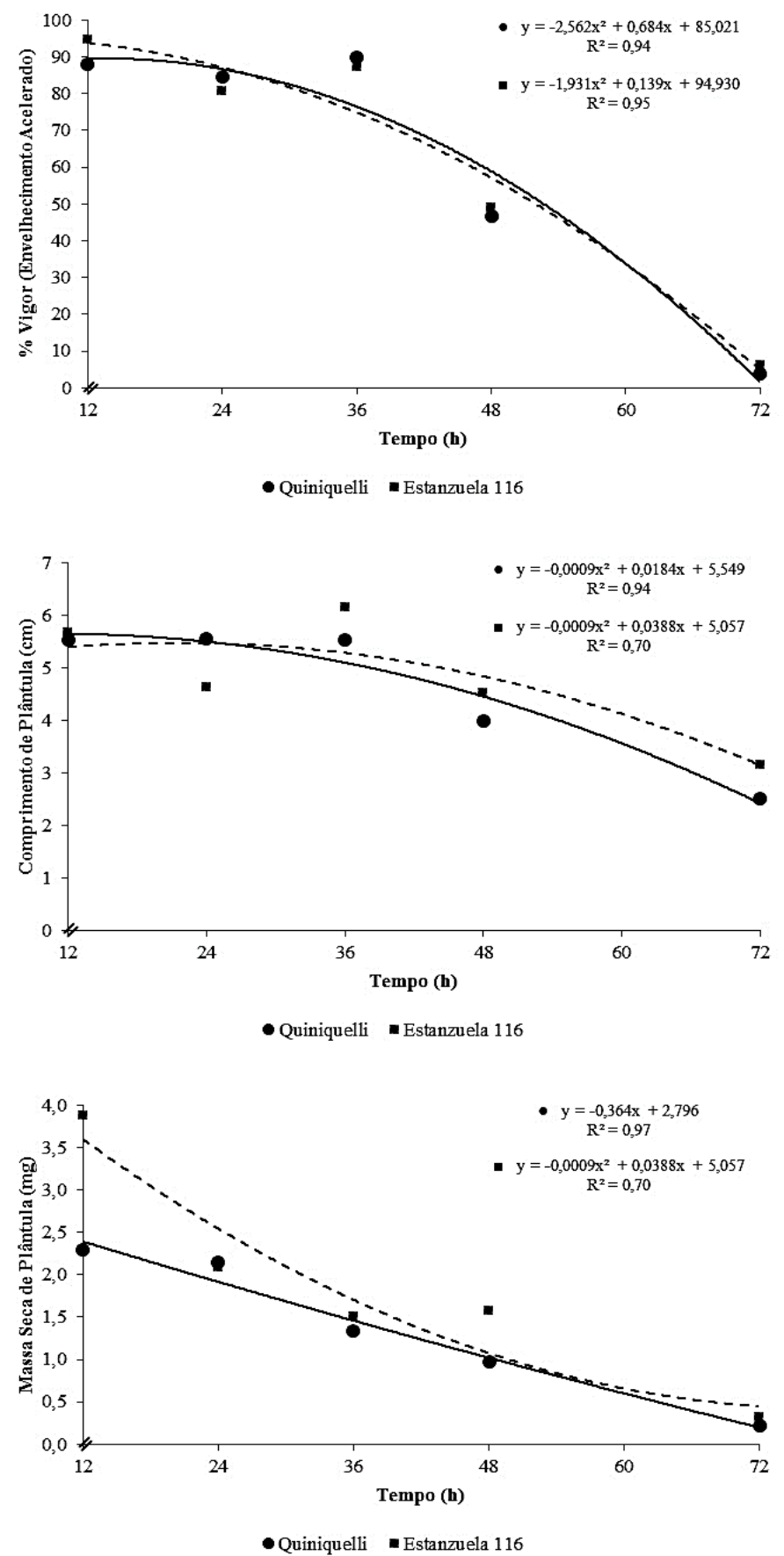

Figura 1. Percentual de vigor, comprimento e massa seca de plântulas das cultivares de trevo vermelho Quiniquelli e Estanzuela 116, submetidas a diferentes tempos de condução do teste de envelhecimento acelerado em solução salina.

Figure 1. Percentage of vigor, length, and dry mass of red clover seedlings of the Quiniquelli and Estanzuela 116 cultivars at different accelerated aging times in a saturated salt solution.

Destaca-se que os resultados encontrados superam a recomendação pela instrução normativa para a cultura, que é de 70\% (MAPA 2005). Porém, no tempo de $48 \mathrm{~h}$ de envelhecimento em solução salina, as sementes responderam ao estresse com redução aproximada de $50 \%$ no vigor em relação aos demais tempos de envelhecimento comentados anteriormente, mostrando que o estresse foi eficaz para ambas as cultivares (Figura 1). 
De forma similar trabalhando com sementes pequenas, BRAGA et al. (2015), FREITAS et al. (2018) e RADKE et al. (2016) constataram para sementes de trevo vermelho, rúcula e coentro, respectivamente, que o tempo de envelhecimento de $48 \mathrm{~h}$ a $41^{\circ} \mathrm{C}$ com solução saturada de $\mathrm{NaCl}$ foi mais eficiente para identificar diferentes níveis de vigor entre lotes. Para crotalária e cenoura, SILVA et al. (2017) e RODO et al. (2000) observaram que a combinação $41^{\circ} \mathrm{C}$ e 96 ou $72 \mathrm{~h}$, respectivamente, são mais eficientes na classificação de lotes em diferentes níveis de vigor.

Avaliações referentes ao crescimento da plântula como o comprimento e massa seca oferecem informações adicionais para a determinação do vigor (BELLÉ et al. 2014). A partir dos resultados encontrados, pode-se constatar que o comportamento destas variáveis foi semelhante ao vigor, podendo-se citar o decréscimo de forma geral com o passar dos tempos de envelhecimento das sementes (Figura 1).

No teste de envelhecimento acelerado realizado com água para análise do vigor, observou-se que o tempo de $36 \mathrm{~h}$ foi suficiente para estressar as sementes (Figura 2). Isso pode ter ocorrido pelo fato de que sementes pequenas tendem a absorver água de forma mais rápida levando à desorganização das membranas celulares durante o envelhecimento das sementes (JAIN et al. 2006).
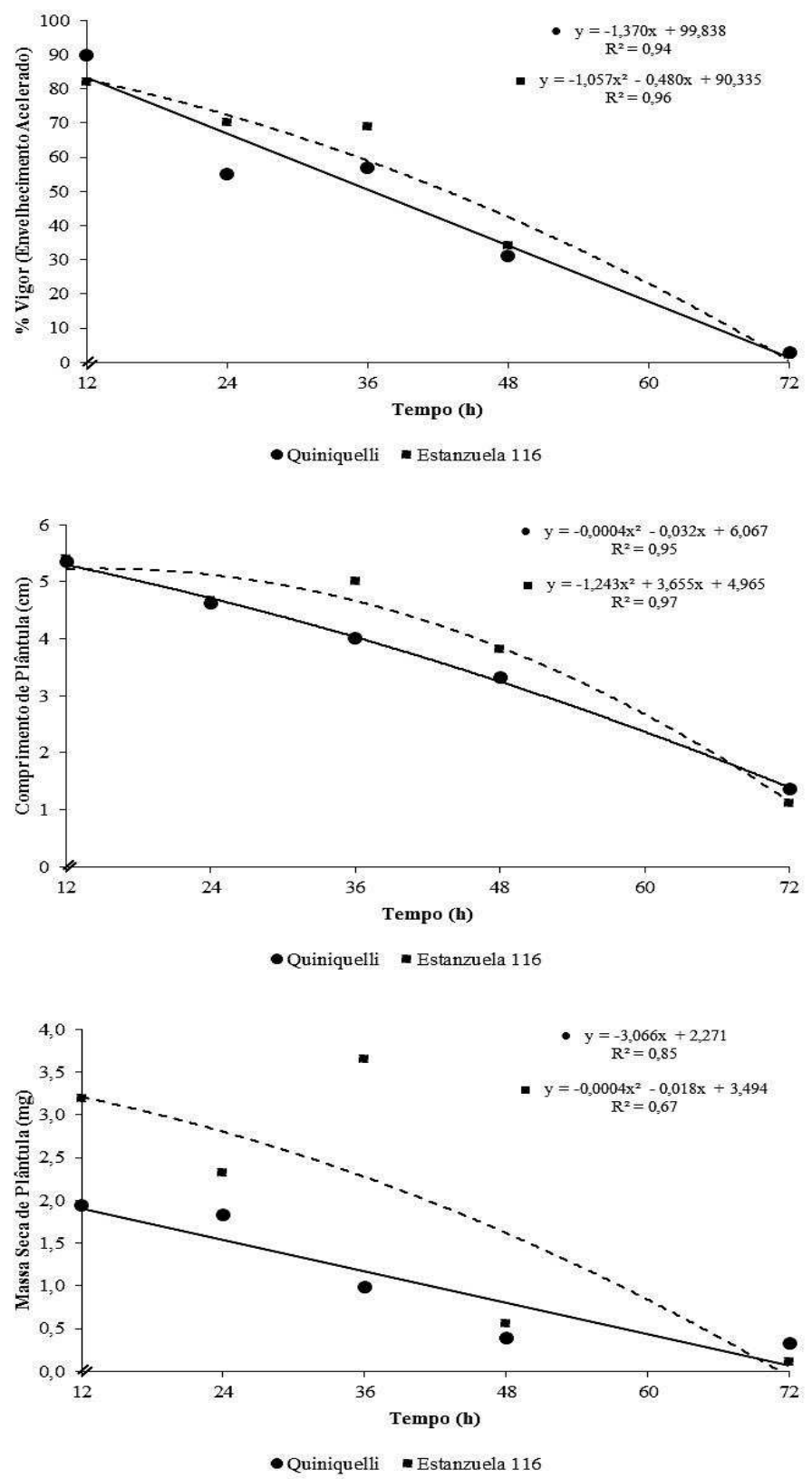

Figura 2. Percentual de vigor, comprimento e massa seca de plântula das cultivares de trevo vermelho Quiniquelli e Estanzuela 116, submetidas a diferentes tempos de condução do teste de envelhecimento acelerado em água.

Figure 2. Percentage of vigor, length, and dry mass of red clover seedlings of the Quiniquelli and Estanzuela 116 cultivars at different accelerated aging times in water. 
Assim, os resultados do presente trabalho sugerem que o emprego de solução salina apresenta resultados mais consistentes para condução do teste de envelhecimento acelerado em sementes de trevo vermelho das cultivares Quiniquelli e Estanzuela 116.

\section{CONCLUSÃO}

No teste conduzido com água, o tempo de $36 \mathrm{~h}$ foi suficiente para estressar as sementes. O tempo de envelhecimento acelerado que melhor caracterizou o vigor de ambas as cultivares foi o de $48 \mathrm{~h}$ sob temperatura de $42{ }^{\circ} \mathrm{C}$, com o uso de solução saturada de $\mathrm{NaCl}$, sendo o mais indicado para as sementes de trevo vermelho.

\section{AGRADECIMENTOS}

Os autores agradecem às agências de fomento Fapesc, PAP, Uniedu e CAPES pelo apoio na realização da pesquisa.

\section{REFERÊNCIAS}

BELLÉ C et al. 2014. Yield and quality of wheat seeds as a function of desiccation stages and herbicides. Journal of Seed Science 36: 63-70.

BRAGA DB et al. 2015. Metodologias de envelhecimento acelerado para avalição do vigor de sementes de trevo vermelho. Enciclopédia Biosfera 11: 1279-1289.

BRASIL. 2009. Ministério da Agricultura, Pecuária e Abastecimento. Regras para análise de sementes. Secretaria de Defesa Agropecuária. Brasília: Mapa/ACS. 399p.

CARVALHO PCF et al. 2010. Forrageiras de Clima Temperado. In: FONSECA DM \& MARTUSCELLO JA. Plantas Forrageiras. Viçosa: UFV. p. 494-537.

FONTANELI RS et al. 2012. Forrageiras para Integração Lavoura-Pecuária-Floresta na Região Sul-brasileira. Brasília: Embrapa. 542p.

FREITAS RMO et al. 2018. Accelerated aging of arugula seeds. Revista Brasileira de Ciências Agrárias 13: 1-6.

JAIN N et al. 2006. Effect of Accelerated Aging on Seeds of Radish (Raphanus sativus L.). Asian Journal of Plant Sciences 5: 461-464.

JIANHUA Z \& McDONALD MD. 1996. The saturated salt accelerated aging test for small-seeded crops. Seed Science and Technology 25: 123-131.

MAPA. 2005. Ministério da Agricultura, Pecuária e Abastecimento. Requisitos Mínimos para Determinação do Valor de Cultivo e Uso de Trevo Vermelho (Trifolium pratense L.) e Inscrição no Registro Nacional de Cultivares - RNC. Brasília: MAPA. 399p.

MARCOS FILHO J. 1999. Teste de envelhecimento acelerado. In: KRZYZANOWSKI FC et al. Vigor de sementes: conceitos e testes. Londrina: ABRATES. p.3.1-3.24.

MONTARDO DP et al. 2003. Análise de trilha para rendimento de sementes em trevo-vermelho (Trifolium pratense L.). Revista Brasileira de Zootecnia 32: 1076-1082.

NAKAGAWA J. 1999. Testes de vigor baseados no desempenho das plântulas. In: KRZYZANOWSKI FC et al. Vigor de sementes: conceitos e testes. Londrina: ABRATES. p.2.1-2.24.

NERY MC et al. 2012. Produção de Sementes de Forrageiras. Lavras: UFLA. p.1-47. (Boletim técnico 88).

PEREIRA MFS et al. 2015. Teste de envelhecimento acelerado para avaliação do potencial fisiológico em sementes de coentro. Semina: Ciências Agrárias 36: 595-606.

RADKE AK et al. 2016. Alternativas metodológicas do teste de envelhecimento acelerado em sementes de coentro. Ciência Rural 46: 95-99.

RODO AB et al. 2000. Metodologia alternativa do teste de envelhecimento acelerado para sementes de cenoura. Scientia Agricola 57: 289-292.

ROSSI RF et al. 2017. Vigor de sementes, população de plantas e desempenho agronômico de soja. Revista de Ciências Agrárias 60: 215-222.

SANTOS HP et al. 2012. Gramíneas forrageiras perenes de inverno. In: FONTANELI RS et al. Forrageiras para integração lavoura-pecuária-floresta na Região Sul-Brasileira. Brasília: EMBRAPA. p.231-246.

SILVA CB et al. 2017. Accelerated aging as vigor test for sunn hemp seeds. Ciência Rural 47: 1-6. 